\title{
Pengenalan Gestur Angka Pada Tangan Menggunakan Arsitektur AlexNet Dan LeNet Pada Metode Convolutional Neural Network
}

\author{
Muhammad Ezar Al Rivan ${ }^{1 *}$, Alvin Setiawan² \\ 1,2) Program Studi Informatika, Fakultas Ilmu Komputer dan Rekayasa, Universitas Multi Data Palembang \\ Jl. Rajawali No. 14, Palembang, Indonesia 30113 \\ Email:meedzhar@mdp.ac.id
}

(Naskah masuk: 07 Juli 2021; diterima untuk diterbitkan: 27 Agustus 2021)

\begin{abstract}
ABSTRAK - Gestur merupakan salah satu jenis komunikasi dengan membentuk suatu objek seperti huruf atau angka pada tangan untuk menyampaikan pesan ataupun sebuah informasi, salah satunya gestur angka pada tangan yang memiliki banyak jenisnya dengan pola yang berbeda untuk setiap pergerakan angka yang terbentuk. Komputer memiliki kendala dalam mengenali gestur angka pada tangan karena perlu metode pengenalan. Salah satu solusi yang dapat dilakukan untuk melakukan pengenalan gestur angka pada tangan kepada komputer adalah menggunakan metode Convolutional Neural Network (CNN) dengan arsitektur AlexNet maupun LeNet. Penelitian ini menggunakan dataset citra gestur angka yang sebelumnya dilakukan tahap pre-processing yang terdiri dari threshold dan resize. Penelitian dilakukan menggunakan 2 pooling layer, yaitu Average Pooling dan Max Pooling kemudian menggunakan optimizer, yaitu SGD, RMSprop, dan Adam. Berdasarkan hasil pengujian yang didapatkan pada penelitian ini, yaitu penggunaan arsitektur AlexNet dengan Average Pooling dan optimizer RMSprop menghasilkan akuras dan f1-score keseluruhan 99,45\% serta penggunaan arsitektur LeNet dengan Average Pooling dan optimizer RMSprop menghasilkan akurasi dan f1-score keseluruhan 99,49\%. Secara keseluruhan penggunaan Average Pooling dengan optimizer RMSprop mendapatkan tingkat akurasi yang paling baik dibandingkan dengan pengujian yang lainnya.
\end{abstract}

Kata Kunci - Gestur; Convolutional Neurral Network; Optimizer; AlexNet; LeNet; Pooling Layer.

\section{Recognition Of Number Gesture On Hand Using Architecture AlexNet And LeNet On Convolutional Neural Network}

\begin{abstract}
Gesture is one type of communication by forming an object such as letters or numbers on the hand to convey a message or information, one of which is the number gesture on the hand which has many types with a different patterns for each movement of the numbers formed. Computer have problems recognizing numeric hand gestures because they needs recognition method. One solution that can be done to perform numeric gesture recognition on a computer is to use the Convolutional Neural Network (CNN) method with AlexNet and LeNet architectures. This study uses a numeric gesture image dataset that was previously carried out in the pre-processing stage consisting of threshold and resize. The research was conducted using 2 pooling layers, namely Average Pooling and Max Pooling and then using an optimizer, namely SGD, RMSprop, and Adam. Based on the test results obtained in this study, the use of the AlexNet architecture with Average Pooling and the RMSprop optimizer resulted in an overall accuracy and f1-score of $99.45 \%$ and the use of the LeNet architecture with Average Pooling and the RMSprop optimizer resulted in an overall accuracy and f1-score of 99.49\%. Overall the use of Average Pooling with the RMSprop optimizer gets the best level of accuracy compared to other tests.
\end{abstract}

Keywords - Gesture; Convolutional Neurral Network; Optimizer; AlexNet; LeNet; Pooling Layer. 


\section{Pendahuluan}

Gestur merupakan bentuk komunikasi nonverbal dengan aksi pada tubuh yang terlihat untuk menyampaikan pesan-pesan tertentu dan dapat digunakan sebagai pengganti komunikasi secara verbal. Gestur juga sering diartikan sebagai gerakan fisik yang mengikuti pergerakan dari jari-jari, tangan, lengan, wajah atau bagian tubuh yang lainnya [1]. Seiring berkembangnya zaman penggunaan gestur tidak hanya dilakukan untuk komunikasi dan pembelajaran dalam kehidupan sehari-hari, penggunaan gestur terutama gestur angka dapat langsung dimengerti oleh setiap manusia yang menggunakan gestur sebagai metode komunikasi atau pembelajaran. Pengenalan gestur memiliki tujuan untuk dapat mengenali makna dari ekspresi gerakan manusia, termasuk didalamnya tangan, lengan, wajah, kepala atau bagian tubuh yang lainnya [2].

Namun kondisinya sedikit berbeda, apabila gestur dikenalkan kepada komputer. Dalam hal ini komputer tidak dapat langsung mengenali sebuah gestur yang ditampilkan, komputer memerlukan sebuah kecerdasan buatan untuk mengenali suatu objek atau gambar. Gestur memiliki banyak jenisnya salah satunya adalah gestur angka. Hal ini menjadi salah satu kesulitan dalam mengenalkan sebuah gestur tersebut kepada komputer.

Beberapa penelitian terkait dengan pengenalan gestur huruf maupun angka yang telah dilakukan dengan berbagai macam metode seperti, penelitian [3] dengan hasil penelitian menunjukan bahwa metode $\mathrm{CNN}$ mencapai tingkat pengenal 6 angka sebesar 100\%, lalu penelitian [4] dengan hasil pengujian yang memiliki akurasi sebesar $98,89 \%$, dan penelitian [5] dengan menghasilkan tingkat pengenalan sebesar 99\%. Kemudian penelitian [6] dengan menghasilkan tingkat akurasi pengenalan sebesar $100 \%$, lalu penelitian [7] menghasilkan tingkat akurasi pengenalan sebesar $99 \%$.

Dalam melakukan pengenalan gestur terdapat berbagai macam metode, salah satunya adalah Convolutional Neural Network (CNN). CNN merupakan klasifikasi objek citra yang banyak digunakan pada penelitian terdahulu dikarenakan menghasilkan tingkat akurasi yang signifikan dalam melakukan pengenalan objek citra [8]. Metode CNN merupakan metode deep learning yang mampu mengenali bentuk objek khususnya citra. $\mathrm{CNN}$ sering digunakan untuk mengatasi permasalahan seperti object detection, image classification dan image segmentation. Adapun penelitian terkait image classification dan image segmentation [9] menghasilkan tingkat akurasi sebesar 96,47, dan penelitian [10] yang menghasilkan tingkat akurasi sebesar 95\%. Sehingga dapat disimpulkan bahwa pengenal gestur dapat dikenali dengan baik dengan menggunakan sebuah kecerdasan buatan dengan metode CNN.

\section{Metode Penelitian}

\subsection{Identifikasi Masalah}

Pada tahap ini dilakukan identifikasi masalah penelitian mengenai bagaimana melakukan pengenalan dalam mengklasifikasikan gestur angka 0 s.d. 5 pada tangan kanan dan tangan kiri berbentuk citra menggunakan arsitektur AlexNet dan LeNet pada metode CNN.

\subsection{Studi Literatur}

Tahapan ini melakukaan pencarian, pengumpulan dan mempelajari beberapa jurnal dan buku yang berkaitan dengan pengenalan gestur angka pada tangan dengan berbagai macam metode serta pengggunaan metode CNN dengan arsitektur AlexNet dan arsitektur LeNet dalam pengenalan atau klasifikasi citra.

\subsection{Pengumpulan Data}

Data yang digunakan dalam penelitian merupakan dataset public yang berjumlah 21.600 data gambar dengan 12 jenis gestur angka pada tangan kanan dan tangan kiri, yaitu gestur angka 0, 1, 2, 3, 4, 5. Dataset yang berjumlah 21.600 data gambar, untuk setiap dataset gambar citra berukuran asli 128x128. Dataset yang digunakan bersumber dari website Kaggle [11]

\subsection{Perancangan Sistem}

Tahap ini dataset yang digunakan akan dibagi menjadi dua fase pelatihan yaitu feature learning atau ekstraksi fitur dan classfication, dengan penggunaan data training sebanyak $75 \%$, data validation sebanyak $15 \%$, dan data testing sebanyak $10 \%$ dari total dataset yang digunakan sebanyak 21.600 data gambar. Proses pengenalan dalam mengklasifikasikan citra gestur angka pada tangan dibagi menjadi 2 tahapan besar yaitu, perancangan sistem dengan arsitektur AlexNet dan perancangan sistem dengan arsitektur LeNet. Tahapan perancangan sistem dengan arsitektur AlexNet dapat dilihat pada Gambar 1.

Pada Gambar 1 merupakan proses dari $\mathrm{CNN}$ dengan rancangan arsitektur AlexNet, proses tersebut memiliki spesifikasi tersendiri. Secara keseluruhan lapisan yang dimiliki arsitektur AlexNet telah diringkas untuk mempermudah proses penelitian yang dapat dilihat pada Tabel 1. 
Tabel 1. Ringkasan Arsitektur AlexNet

\begin{tabular}{cccccc}
\hline Layer & $\begin{array}{c}\text { Feature } \\
\text { Maps }\end{array}$ & Size & $\begin{array}{c}\text { Kernel } \\
\text { Size }\end{array}$ & $\begin{array}{c}\text { Stri } \\
\text { de }\end{array}$ & $\begin{array}{c}\text { Activa- } \\
\text { tion }\end{array}$ \\
\hline Input & 3 & $227 \times 227$ & - & - & - \\
\hline Conv & 16 & $55 \times 55$ & $11 \times 11$ & 4 & ReLU \\
\hline Pooling & 16 & $27 \times 27$ & $3 \times 3$ & 2 & - \\
\hline Conv & 32 & $23 \times 23$ & $5 \times 5$ & 1 & ReLU \\
\hline Pooling & 32 & $11 \times 11$ & $3 \times 3$ & 2 & - \\
\hline Conv & 64 & $9 \times 9$ & $3 \times 3$ & 1 & ReLU \\
\hline Conv & 64 & $7 \times 7$ & $3 \times 3$ & 1 & ReLU \\
\hline Conv & 32 & $5 \times 5$ & $3 \times 3$ & 1 & ReLU \\
\hline Pooling & 32 & $2 \times 2$ & $3 \times 3$ & 2 & - \\
\hline FC & - & 32 & - & - & ReLU \\
\hline FC & - & 32 & - & - & ReLU \\
\hline FC - & - & 12 & - & - & Softmax \\
Output & & & & & \\
\hline
\end{tabular}

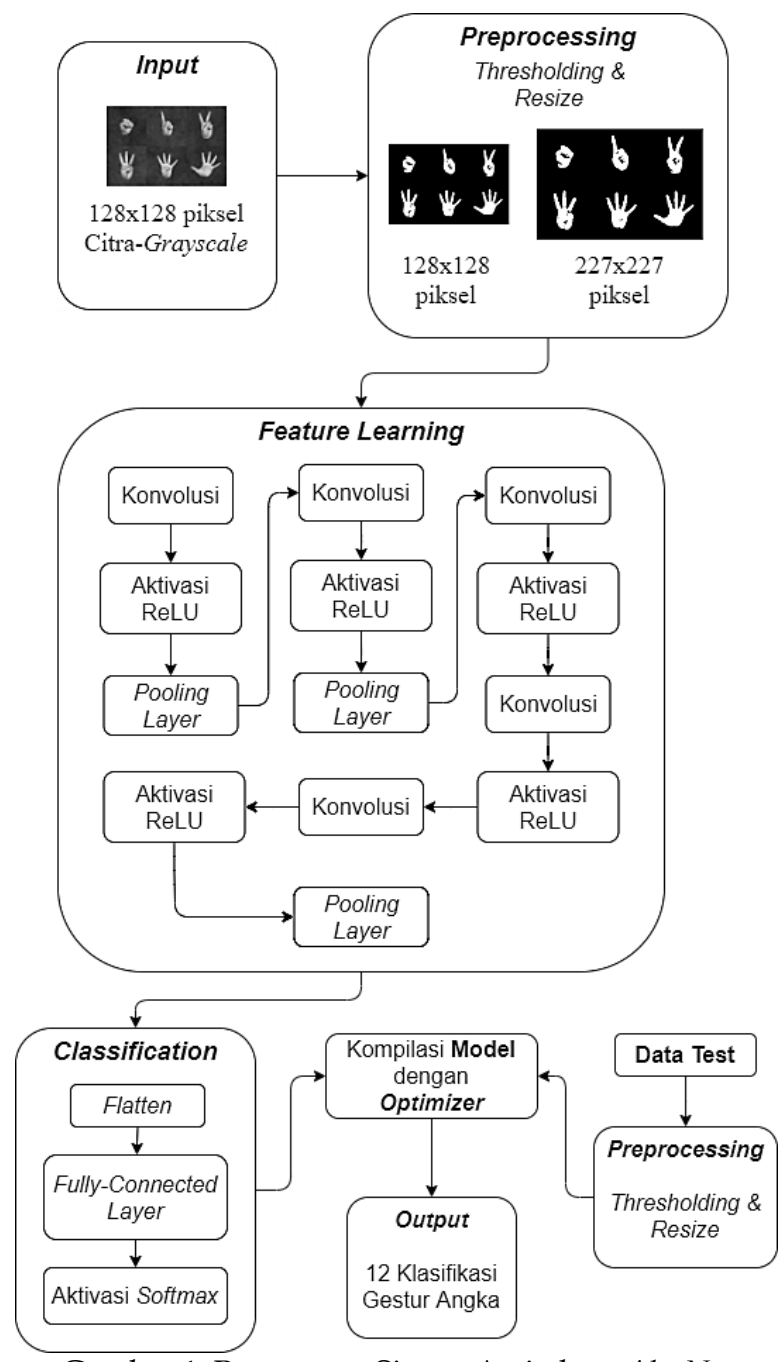

Gambar 1. Rancangan Sistem Arsitektur AlexNet

Hasil dimensi keluaran atau size dari masingmasing lapisan didapatkan dengan menggunakan Persamaan 1 dan 2 [12].

$$
\text { Size Weight }=\left(\frac{W-F_{W}+2 P}{S_{w}}\right)+1
$$

$$
\text { Size Height }=\left(\frac{H-F_{h}+2 P}{S_{h}}\right)+1
$$

Dimana $W$ (width) dan H(Height) adalah ukuran dari sebuah citra input, $F_{w}$ (width) dan $F_{h}$ (Height) adalah filter atau kernel, $P$ adalah padding suatu citra dengan ukuran default yang bernilai 0 (nol), dan $S_{w}$ (width) dan $S_{h}$ (Height) adalah ukuran dari stride atau pergeseran suatu kernel size [12].

Tahapan perancangan sistem dengan arsitektur LeNet dapat dilihat pada Gambar 2. Pada Gambar 2 merupakan proses dari $\mathrm{CNN}$ dengan rancangan arsitektur LeNet, proses tersebut memiliki spesifikasi tersendiri.

Secara keseluruhan lapisan yang dimiliki arsitektur LeNet telah diringkas untuk mempermudah proses penelitian yang dapat dilihat pada Tabel 2.

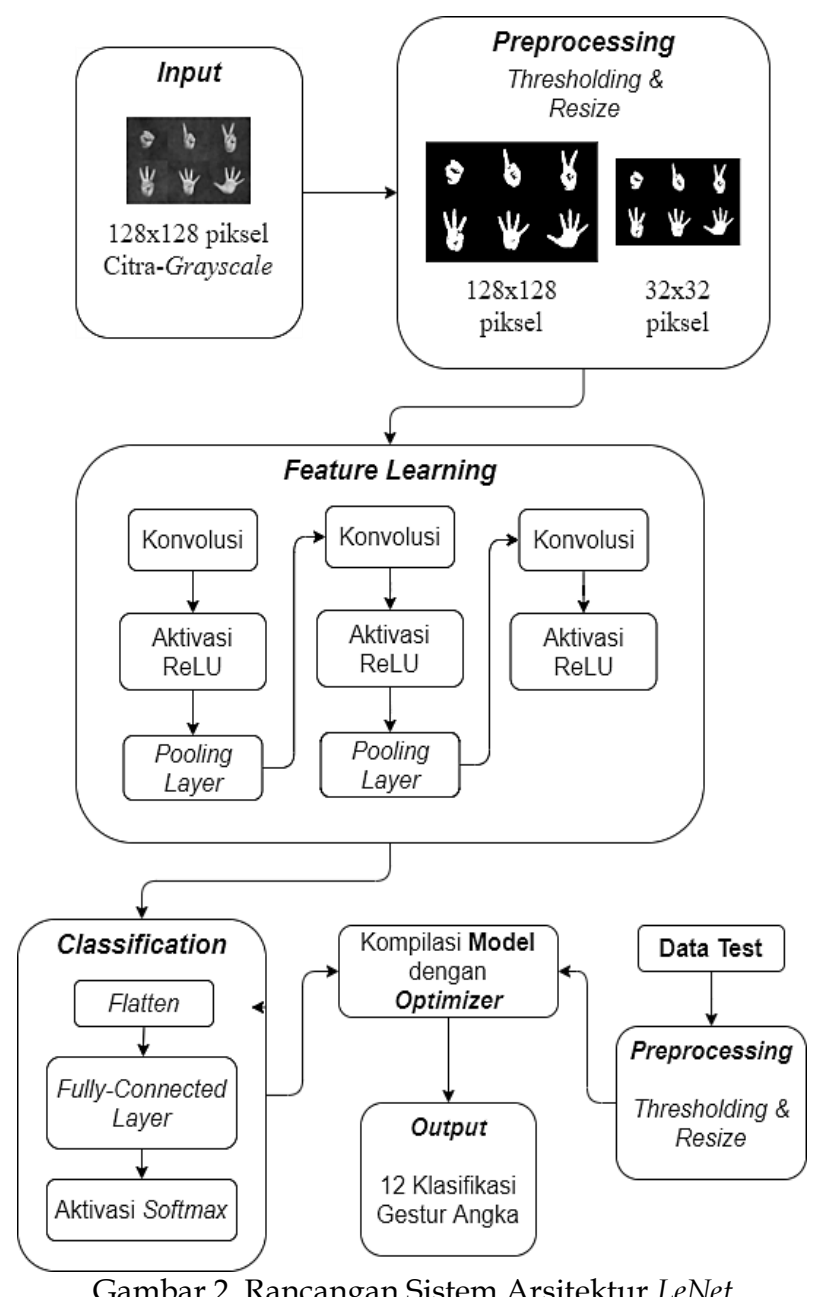

Gambar 2. Rancangan Sistem Arsitektur LeNet 
Tabel 2. Ringkasan Arsitektur LeNet

\begin{tabular}{cccccc}
\hline Layer & $\begin{array}{c}\text { Feature } \\
\text { Maps }\end{array}$ & Size & $\begin{array}{c}\text { Kernel } \\
\text { Size }\end{array}$ & Stride & Activation \\
\hline Input & 3 & $32 \times 32$ & - & - & - \\
\hline Conv & 6 & $28 \times 28$ & $5 \times 5$ & 1 & ReLU \\
\hline Pooling & 6 & $14 \times 14$ & $2 \times 2$ & 2 & - \\
\hline Conv & 16 & $10 \times 10$ & $5 \times 5$ & 1 & ReLU \\
\hline Pooling & 16 & $5 \times 5$ & $2 \times 2$ & 2 & - \\
\hline Conv & 120 & $1 \times 1$ & $5 \times 5$ & 1 & ReLU \\
\hline FC & - & 32 & - & - & ReLU \\
\hline FC- & - & 12 & - & - & Softmax \\
Output & & & & &
\end{tabular}

Hasil dimensi keluaran atau size dari masingmasing lapisan didapatkan dengan menggunakan Persamaan 1 dan 2 [12].

\subsection{Implementasi}

Tahap implementasi ini akan menerapkan rancangan CNN dengan arsitektur AlexNet dan LeNet terhadap citra gestur angka pada tangan. Tahap ini akan diimplementasikan kedalam bentuk bahasa pemrogramman yaitu Matlab dan Python. Untuk tahap preprocessing yaitu threshold menggunakan tools Matlab dilanjutkan dengan preprocessing kedua yaitu resize dan proses keseluruhan CNN dengan arsitektur AlexNet dan LeNet menggunakan plugin Jupyter Notebook pada tools Visual Studio Code.

\subsection{Pengujian}

Proses pengujian dilakukan dengan melakukan tunning parameter yang kemudian akan digunakan untuk melakukan prediksi terhadap data testing dengan tujuan untuk menghasilkan tingkat akurasi yang terbaik dalam mengklasifikasikan citra gestur angka pada tangan. Rincian skenario pengujian dapat dilihat pada Tabel 3.

Tabel 3. Rincian Skenario Pengujian

\begin{tabular}{cccc}
\hline Skenario & Arsitektur & Pooling Layer & Optimizer \\
\hline $\mathbf{1}$ & AlexNet & Average Pooling & SGD \\
\hline $\mathbf{2}$ & AlexNet & Average Pooling & RMSprop \\
\hline $\mathbf{3}$ & AlexNet & Average Pooling & Adam \\
\hline $\mathbf{4}$ & AlexNet & Max Pooling & SGD \\
\hline $\mathbf{5}$ & AlexNet & Max Pooling & RMSprop \\
\hline $\mathbf{6}$ & AlexNet & Max Pooling & Adam \\
\hline $\mathbf{7}$ & LeNet & Average Pooling & SGD \\
\hline $\mathbf{8}$ & LeNet & Average Pooling & RMSprop \\
\hline $\mathbf{9}$ & LeNet & Average Pooling & Adam \\
\hline $\mathbf{1 0}$ & LeNet & Max Pooling & SGD \\
\hline $\mathbf{1 1}$ & LeNet & Max Pooling & RMSprop \\
\hline $\mathbf{1 2}$ & LeNet & Max Pooling & Adam \\
\hline
\end{tabular}

\subsection{Evaluasi}

Pada tahap ini dilakukan evaluasi dari tahapan sebelumnya yaitu pengujian. Evaluasi yang dilakukan untuk data per kelas sebanyak 12 kelas dengan menggunakan metode Confusion Matrix yang terdiri dari Precision, Recall, Accuracy dan F1-Score.

\section{HASIl DAN PEMBAHASAN}

\subsection{Hasil Thresholding terhadap Citra Gestur Angka Pada Tangan}

Pada tahap ini menjelaskan proses dari tahap preprocessing yaitu metode thresholding dengan mengubah citra grayscale menjadi citra hitam putih dengan tujuan mendapatkan bentuk dari citra yang dihasilkan. Citra hasil metode thresholding dapat dilihat pada Gambar 3, dengan jenis gestur angka yang terdiri dari 12 jenis kelas, yaitu $0 R, 1 R, 2 R, 3 R$, $4 \mathrm{R}, 5 \mathrm{R}, 0 \mathrm{~L}, 1 \mathrm{~L}, 2 \mathrm{~L}, 3 \mathrm{~L}, 4 \mathrm{~L}, 5 \mathrm{~L}$.

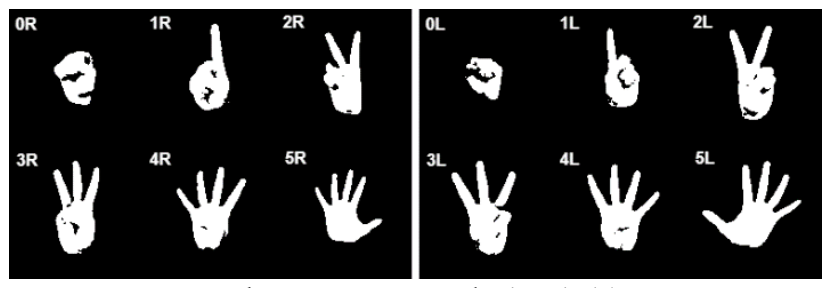

Gambar 3. Citra Hasil Thresholding

\subsection{Implementasi Metode Convolutional Neural Network (CNN)}

Ringkasan dari metode CNN dengan arsitektur AlexNet dan LeNet akan diimplementasikan untuk melakukan training model pada dataset sebanyak 25 kali atau 25 epoch dengan menggunakan 2 jenis pooling layer, 3 jenis optimizer dengan learning rate sebesar 1.0E-5 atau 0.00001. Kemudian proses penyimpanan model menggunakan sebuah checkpoint (Checkpoint Callback) untuk menyimpan model dengan tingkat akurasi yang lebih baik dari epoch sebelumnya.

Dataset yang digunakan terdiri dari folder dataset training dan validation dengan rasio dataset trainining sebanyak $75 \%$ dengan jumlah per kelas (1.350 gambar) dan daset validation sebanyak $15 \%$ dengan jumlah per kelas (270 gambar) dan folder dataset testing sebanyak $10 \%$ dengan jumlah per kelas (180 gambar) dari total dataset yang digunakan sebanyak 21.600 data gambar dengan total kelas data sebanyak 12 kelas.

\subsection{Implementasi Metode CNN dengan Arsitektur AlexNet}

Proses training dataset pada arsitektur AlexNet dapat dilihat pada Gambar 4.

Params yang dihasilkan pada lapisan convolution (Conv2D) dan lapisan fully-connected (Dense) diperoleh dengan menggunakan Persamaan 3 dan 4 [13].

$$
\text { Conv }=(N \times M \times L+\text { bias }) \times K
$$

Dimana $N$ adalah kernel size width, $M$ adalah kernel size height, $L$ adalah feature maps input, dan $K$ adalah feature maps output. 
Dense $=(N \times$ bias $) \times M$

Dimana $N$ merupakan node input dan $M$ adalah node output. Nilai bias dalam kasus ini bernilai 1 .

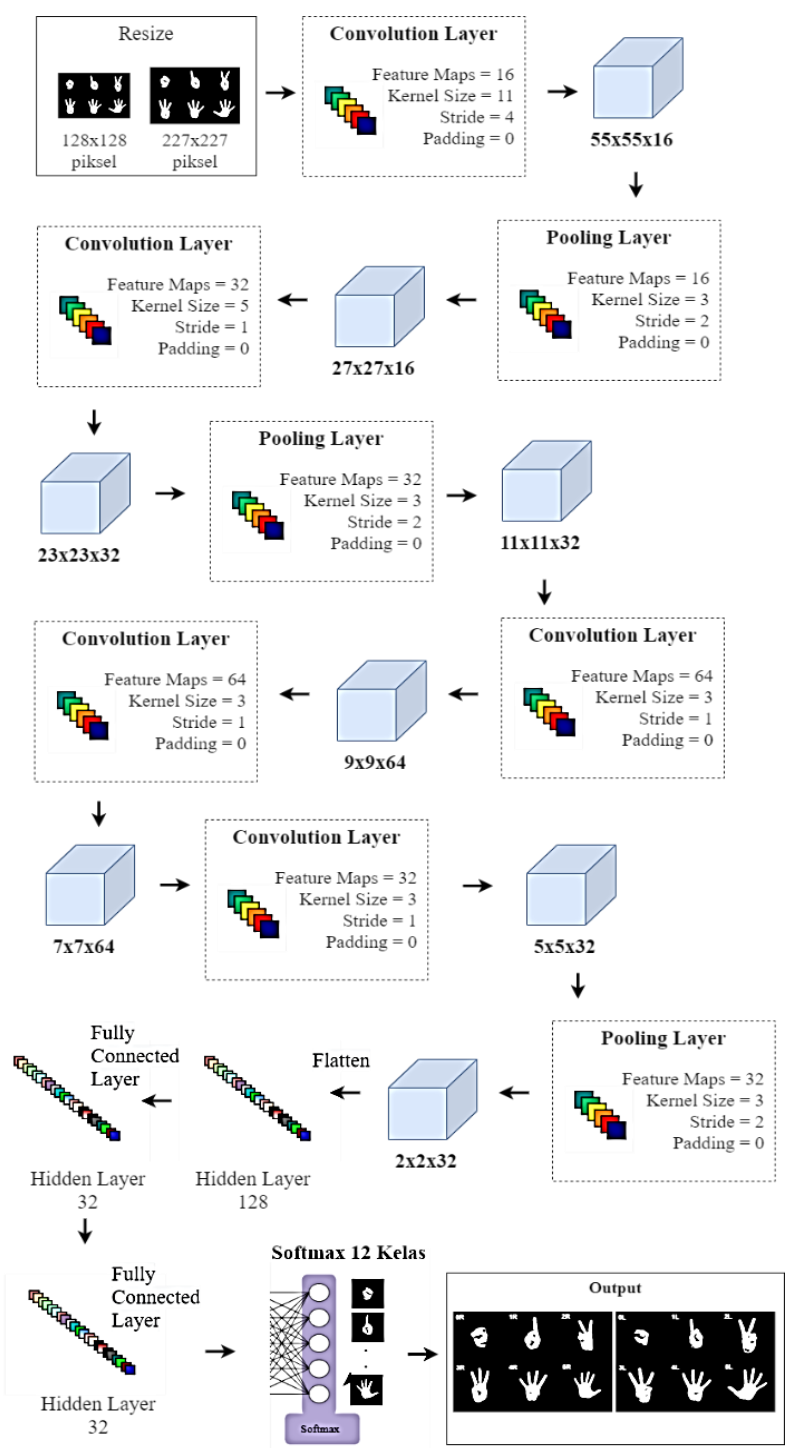

Gambar 4. Proses Training pada Arsitektur AlexNet

Ringkasan hasil model dari hasil implementasi arsitektur AlexNet dengan menggunakan average dan max pooling dapat dilihat pada Tabel 4 dan Tabel 5.

Output shape yang dihasilkan pada lapisan convolution dan fully-connected didapatkan menggunakan Persamaan 1 dan 2. Kemudian output shape pada lapisan flatten didapatkan dengan menggunakan Persamaan 5 [14].

flatten $=$ Output $_{\text {witdh }} \times$ Output $_{\text {height }} \times f$ (5)

Dimana $f$ adalah feature map dan Output yang dimaksud adalah hasil keluaran dari lapisan sebelum flatten. Pada lapisan pooling layer tidak menghasilkan nilai param dikarenakan lapisan ini hanya digunakan untuk memperkecil ukuran dimensi citra [15]. Semua tahap dari proses lapisan convolution dan lapisan fully-connected menggunakan aktivasi ReLU dengan tujuan menghasilkan output piksel tanpa adanya nilai negatif [16], dan lapisan akhir menggunakan aktivasi softmax untuk menghitung probabilitas dari masingmasing kelas.

Tabel 4. Ringkasan Model Hasil Implementasi Arsitektur AlexNet dengan Average Pooling

\begin{tabular}{ccc}
\hline Layer (type) & Output Shape & Param \# \\
\hline conv2d (Conv2D) & (None, 55, 55,16) & 5824 \\
\hline $\begin{array}{c}\text { average_pooling2d } \\
\text { (AveragePooling2D) }\end{array}$ & (None, 27. 27, 16) & 0 \\
\hline conv2d_1 (Conv2D) & (None, 23, 23, 32) & 12832 \\
\hline $\begin{array}{c}\text { average_pooling2d_1 } \\
\text { (AveragePooling2D) }\end{array}$ & (None, 11, 11, 32) & 0 \\
\hline conv2d_2 (Conv2D) & (None, 9, 9, 64) & 18496 \\
\hline conv2d_3 (Conv2D) & (None, 7, 7, 64) & 36928 \\
\hline conv2d_4 (Conv2D) & (None, 5, 5, 32) & 18464 \\
\hline $\begin{array}{c}\text { average_pooling2d_2 } \\
\text { (AveragePooling2D) }\end{array}$ & (None, 2, 2, 32) & 0 \\
\hline flatten (Flatten) & (None, 128) & 0 \\
\hline dense (Dense) & (None, 32) & 4128 \\
\hline dense_1 (Dense) & (None, 32) & 1056 \\
\hline dense_2 (Dense) & (None, 12) & 396 \\
\hline
\end{tabular}

Total Param : 98124

Trainale params : 98124

Non-trainable params : 0

Tabel 5. Ringkasan Model Hasil Implementasi Arsitektur AlexNet dengan Max Pooling

\begin{tabular}{ccc}
\hline Layer(type) & Output Shape & Param \# \\
\hline conv2d (Conv2D) & (None, 55, 55,16) & 5824 \\
\hline $\begin{array}{c}\text { average_pooling2d } \\
\text { (AveragePooling2D) }\end{array}$ & (None, 27. 27, 16) & 0 \\
\hline conv2d_1 (Conv2D) & (None, 23, 23, 32) & 12832 \\
\hline $\begin{array}{c}\text { average_pooling2d_1 } \\
\text { (AveragePooling2D) }\end{array}$ & (None, 11, 11, 32) & 0 \\
\hline conv2d_2 (Conv2D) & (None, 9, 9, 64) & 18496 \\
\hline conv2d_3 (Conv2D) & (None, 7, 7, 64) & 36928 \\
\hline conv2d_4 (Conv2D) & (None, 5, 5, 32) & 18464 \\
\hline $\begin{array}{c}\text { average_pooling2d_2 } \\
\text { (AveragePooling2D) }\end{array}$ & (None, 2, 2, 32) & 0 \\
\hline flatten (Flatten) & (None, 128) & 0 \\
\hline dense (Dense) & (None, 32) & 4128 \\
\hline dense_1 (Dense) & (None, 32) & 1056 \\
\hline dense_2 (Dense) & (None, 12) & 396
\end{tabular}

Total Param : 98124

Trainale params : 98124

Non-trainable params : 0

\subsection{Implementasi Metode $\mathrm{CNN}$ dengan Arsitektur LeNet}

Ringkasan hasil model dari hasil implementasi arsitektur AlexNet dengan menggunakan average pooling dan max pooling dapat dilihat pada Tabel 6 dan Tabel 7.

Tabel 6. Ringkasan Model Hasil Implementasi Arsitektur LeNet dengan Average Pooling

\begin{tabular}{ccc} 
Layer(type) & Output Shape & Param \# \\
\hline conv2d (Conv2D) & (None, 28, 28,6) & 456 \\
$\begin{array}{c}\text { average_pooling2d } \\
\text { (AveragePooling2D) }\end{array}$ & (None, 14. 14, 6) & 0 \\
conv2d_1 (Conv2D) & (None, 10, 10, 16) & 2416
\end{tabular}




\begin{tabular}{|c|c|c|}
\hline $\begin{array}{l}\text { average_pooling2d_1 } \\
\text { (AveragePooling2D) }\end{array}$ & (None, 5, 5, 16) & 0 \\
\hline conv2d_2 (Conv2D) & (None, $1,1,120)$ & 48120 \\
\hline flatten (Flatten) & (None, 120) & 0 \\
\hline dense (Dense) & (None, 84) & 10164 \\
\hline dense_1(Dense) & (None, 12) & 1020 \\
\hline \multicolumn{3}{|c|}{$\begin{array}{l}\text { Total Param : } 62176 \\
\text { Trainale params : } 62176 \\
\text { Non-trainable params : } 0\end{array}$} \\
\hline \multicolumn{3}{|c|}{$\begin{array}{l}\text { Tabel 7. Ringkasan Model Hasil Implementasi } \\
\text { Arsitektur LeNet dengan Max Pooling }\end{array}$} \\
\hline Layer (type) & Output Shape & Param \# \\
\hline conv2d (Conv2D) & (None, 28, 28,6) & 456 \\
\hline $\begin{array}{l}\text { average_pooling } 2 d \\
\text { (AveragePooling2D) }\end{array}$ & (None, 14. 14, 6) & 0 \\
\hline conv2d_1 (Conv2D) & (None, 10, 10, 16) & 2416 \\
\hline $\begin{array}{l}\text { average_pooling } 2 d \_1 \\
\text { (AveragePooling2D) }\end{array}$ & (None, 5, 5, 16) & 0 \\
\hline conv2d_2 (Conv2D) & (None, 1, 1, 120) & 48120 \\
\hline flatten (Flatten) & (None, 120) & 0 \\
\hline dense (Dense) & (None, 84) & 10164 \\
\hline dense_1 (Dense) & (None, 12) & 1020 \\
\hline \multicolumn{3}{|c|}{$\begin{array}{l}\text { Total Param : } 62176 \\
\text { Trainale params : } 62176 \\
\text { Non-trainable params : } 0\end{array}$} \\
\hline
\end{tabular}

Proses training dataset pada arsitektur LeNet dapat dilihat pada Gambar 5.

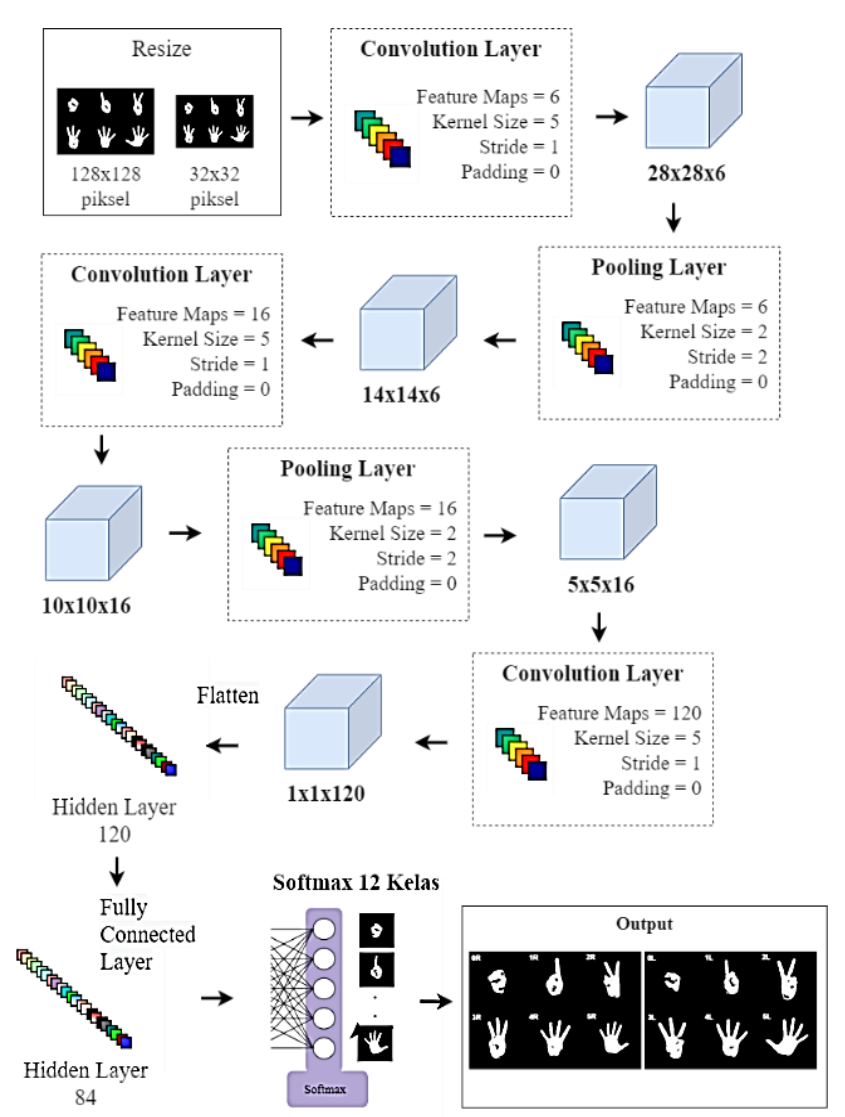

Gambar 5. Proses Training pada Arsitektur LeNet

\subsection{Implementasi Skenario Pengujian}

Pada tahap ini menjelaskan hasil implementasi dengan pengujian per-kelas dan 12 skenario pengujian yang telah dilakukan dengan menggunakan dataset training dan validation yang belum dilakukan proses pelatihan model pada arsitektur AlexNet dan LeNet.

\section{A. Arsitektur AlexNet menggunakan Average Pooling dengan Optimizer SGD}

Hasil yang diperoleh pada skenario pertama dapat dlihat pada Tabel 8.

Tabel 8. Hasil Pengujian Skenario ke-1

\begin{tabular}{ccccc}
\hline \multirow{2}{*}{ Kelas } & \multicolumn{4}{c}{ Confusion Matrix (\%) } \\
\cline { 2 - 5 } & Accuracy & Precision & Recall & F1-Score \\
\hline 0L & 47.78 & 87.76 & 47.78 & 61.87 \\
\hline 0R & 86.67 & 56.93 & 86.67 & 68.72 \\
\hline 1L & 48.89 & 30.45 & 48.89 & 37.53 \\
\hline 1R & 53.89 & 67.63 & 53.89 & 59.88 \\
\hline 2L & 3.89 & 35 & 3.89 & 7 \\
\hline 2R & 32.78 & 37.58 & 32.78 & 35.01 \\
\hline 3L & 56.11 & 60.12 & 56.11 & 58.05 \\
\hline 3R & 42.78 & 48.43 & 42.78 & 45.43 \\
\hline 4L & 35 & 42.28 & 35 & 38.3 \\
\hline 4R & 78.33 & 66.51 & 78.33 & 71.94 \\
\hline 5L & 88.89 & 66.12 & 88.89 & 75.83 \\
\hline 5R & 87.22 & 63.31 & 87.22 & 73.36 \\
\hline Overall & $\mathbf{5 5 . 1 9}$ & $\mathbf{5 5 . 1 5}$ & $\mathbf{5 5 . 1 9}$ & $\mathbf{5 2 . 7 4}$ \\
\hline & & & &
\end{tabular}

Total Waktu Training

1345.64 detik

B. Arsitektur AlexNet menggunakan Average Pooling dengan Optimizer RMSprop

Hasil yang diperoleh pada skenario kedua dapat dlihat pada Tabel 9.

Tabel 9. Hasil Pengujian Skenario ke-2

\begin{tabular}{ccccc}
\hline \multirow{2}{*}{ Kelas } & \multicolumn{4}{c}{ Confusion Matrix (\%) } \\
\cline { 2 - 5 } & Accuracy & Precision & Recall & F1-Score \\
\hline 0L & 100 & 100 & 100 & 100 \\
\hline 0R & 100 & 100 & 100 & 100 \\
\hline 1L & 97.78 & 100 & 97.78 & 98.88 \\
\hline 1R & 100 & 97.83 & 100 & 98.9 \\
\hline 2L & 98.89 & 100 & 98.89 & 99.44 \\
\hline 2R & 98.89 & 98.89 & 98.89 & 98.89 \\
\hline 3L & 100 & 97.83 & 100 & 98.9 \\
\hline 3R & 98.89 & 98.89 & 98.89 & 98.89 \\
\hline 4L & 100 & 100 & 100 & 100 \\
\hline 4R & 98.89 & 100 & 98.89 & 99.44 \\
\hline 5L & 100 & 100 & 100 & 100 \\
\hline 5R & 100 & 100 & 100 & 100 \\
\hline Overall & $\mathbf{9 9 . 4 4}$ & $\mathbf{9 9 . 4 5}$ & $\mathbf{9 9 . 4 4}$ & $\mathbf{9 9 . 4 4}$ \\
\hline \multicolumn{7}{c}{ Total Waktu Training } & $\mathbf{1 5 0 9 . 1 7}$ detik
\end{tabular}

C. Arsitektur AlexNet menggunakan Average Pooling dengan Optimizer Adam

Hasil yang diperoleh pada skenario ketiga dapat dlihat pada Tabel 10. 
Tabel 10. Hasil Pengujian Skenario ke-3

\begin{tabular}{|c|c|c|c|c|}
\hline \multirow{2}{*}{ Kelas } & \multicolumn{4}{|c|}{ Confusion Matrix (\%) } \\
\hline & Accuracy & Precision & Recall & F1-Score \\
\hline $\mathbf{0 L}$ & 100 & 99.45 & 100 & 99.72 \\
\hline OR & 100 & 57.69 & 100 & 73.17 \\
\hline $1 \mathrm{~L}$ & 42.78 & 100 & 42.78 & 59.92 \\
\hline 1R & 77.78 & 99.29 & 77.78 & 87.23 \\
\hline $2 \mathrm{~L}$ & 98.89 & 94.68 & 98.89 & 96.74 \\
\hline 2R & 92.22 & 94.32 & 92.22 & 93.26 \\
\hline $3 \mathrm{~L}$ & 92.22 & 93.79 & 92.22 & 93 \\
\hline 3R & 91.11 & 96.47 & 91.11 & 93.71 \\
\hline $4 \mathrm{~L}$ & 100 & 100 & 100 & 100 \\
\hline $4 \mathbf{R}$ & 100 & 99.45 & 100 & 99.72 \\
\hline $5 \mathrm{~L}$ & 100 & 99.45 & 100 & 99.72 \\
\hline $5 \mathbf{R}$ & 100 & 91.84 & 100 & 95.74 \\
\hline Overall & 91.25 & 93.87 & 91.25 & 91 \\
\hline \multicolumn{3}{|c|}{ Total Waktu Training } & \multicolumn{2}{|c|}{1622.69 detik } \\
\hline
\end{tabular}

\section{Arsitektur AlexNet menggunakan Max Pooling dengan Optimizer SGD}

Hasil yang diperoleh pada skenario keempaat dapat dlihat pada Tabel 11.

Tabel 11. Hasil Pengujian Skenario ke-4

\begin{tabular}{ccccc}
\hline \multirow{2}{*}{ Kelas } & \multicolumn{5}{c}{ Confusion Matrix (\%) } \\
\cline { 2 - 5 } & Accuracy & Precision & Recall & F1-Score \\
\hline 0L & 80 & 90 & 80 & 87.71 \\
\hline 0R & 88.33 & 80.71 & 88.33 & 84.35 \\
\hline 1L & 85.56 & 77.78 & 85.56 & 81.48 \\
\hline 1R & 54.44 & 67.59 & 54.44 & 60.31 \\
\hline 2L & 53.89 & 56.07 & 53.89 & 54.96 \\
\hline 2R & 45 & 46.29 & 45 & 45.63 \\
\hline 3L & 52.22 & 59.12 & 52.22 & 55.46 \\
\hline 3R & 56.67 & 56.35 & 56.67 & 56.51 \\
\hline 4L & 90.56 & 84.9 & 90.56 & 87.63 \\
\hline 4R & 87.22 & 83.96 & 87.22 & 85.56 \\
\hline 5L & 96.11 & 92.02 & 96.11 & 94.02 \\
\hline 5R & 96.67 & 84.88 & 96.67 & 90.39 \\
\hline Overall & $\mathbf{7 3 . 8 9}$ & $\mathbf{7 3 . 3}$ & $\mathbf{7 3 . 8 9}$ & $\mathbf{7 3 . 4 2}$ \\
\hline \multicolumn{7}{c}{ Total Waktu Training } & $\mathbf{1 3 2 8 . 4 6}$ detik
\end{tabular}

\section{E. Arsitektur AlexNet menggunakan Max Pooling dengan Optimizer RMSprop}

Hasil yang diperoleh pada skenario kelima dapat dlihat pada Tabel 12.

Tabel 12. Hasil Pengujian Skenario ke-5

\begin{tabular}{ccccc}
\hline \multirow{2}{*}{ Kelas } & \multicolumn{4}{c}{ Confusion Matrix $\mathbf{( \% )}$} \\
\cline { 2 - 5 } & Accuracy & Precision & Recall & F1-Score \\
\hline 0L & 100 & 97.83 & 100 & 98.9 \\
\hline 0R & 100 & 100 & 100 & 100 \\
\hline 1L & 98.89 & 97.27 & 98.89 & 98.07 \\
\hline 1R & 97.78 & 96.7 & 97.78 & 97.24 \\
\hline 2L & 96.67 & 98.31 & 96.67 & 97.48 \\
\hline 2R & 97.78 & 98.32 & 97.78 & 98.05 \\
\hline 3L & 96.11 & 98.3 & 96.11 & 97.19 \\
\hline 3R & 98.89 & 98.34 & 98.89 & 98.61 \\
\hline 4L & 97.22 & 98.87 & 97.22 & 98.04 \\
\hline 4R & 99.44 & 99.44 & 99.44 & 99.44 \\
\hline 5L & 100 & 98.9 & 100 & 99.45 \\
\hline 5R & 99.44 & 100 & 99.44 & 99.72 \\
\hline Overall & $\mathbf{9 8 . 5 2}$ & $\mathbf{9 8 . 5 2}$ & $\mathbf{9 8 . 5 2}$ & $\mathbf{9 8 . 5 2}$ \\
\hline \multicolumn{7}{r}{ Total Waktu Training } & $\mathbf{1 5 9 5 . 3 5}$ detik \\
\hline
\end{tabular}

\section{F. Arsitektur AlexNet menggunakan Max Pooling} dengan Optimizer Adam

Hasil yang diperoleh pada skenario keenam dapat dlihat pada Tabel 13.

Tabel 13. Hasil Pengujian Skenario ke-6

\begin{tabular}{|c|c|c|c|c|}
\hline \multirow{2}{*}{ Kelas } & \multicolumn{4}{|c|}{ Confusion Matrix (\%) } \\
\hline & Accuracy & Precision & Recall & F1-Score \\
\hline OL & 70 & 100 & 70 & 82.32 \\
\hline OR & 99.44 & 99.44 & 99.44 & 99.44 \\
\hline 1L & 88.33 & 77.18 & 88.33 & 82.38 \\
\hline 1R & 93.89 & 81.25 & 93.89 & 87.11 \\
\hline $2 \mathrm{~L}$ & 91.67 & 93.75 & 91.67 & 92.7 \\
\hline $2 \mathbf{R}$ & 92.22 & 93.79 & 92.22 & 93 \\
\hline $3 \mathrm{~L}$ & 93.89 & 96.06 & 93.89 & 94.94 \\
\hline 3R & 95.56 & 91.01 & 95.56 & 93.22 \\
\hline $4 \mathrm{~L}$ & 98.33 & 96.2 & 98.33 & 97.25 \\
\hline $4 \mathbf{R}$ & 99.44 & 94371 & 99.44 & 97.02 \\
\hline $5 \mathrm{~L}$ & 98.33 & 98.88 & 98.33 & 98.61 \\
\hline $5 \mathbf{R}$ & 94.44 & 100 & 94.44 & 97.14 \\
\hline Overall & 92.96 & 93.52 & 92.96 & 92.93 \\
\hline \multicolumn{3}{|c|}{ Total Waktu Training } & \multicolumn{2}{|c|}{1700.39 detik } \\
\hline
\end{tabular}

\section{G. Arsitektur LeNet menggunakan Average} Pooling dengan Optimizer SGD

Hasil yang diperoleh pada skenario ketujuh dapat dlihat pada Tabel 14.

Tabel 14. Hasil Pengujian Skenario ke-7

\begin{tabular}{ccccc}
\hline \multirow{2}{*}{ Kelas } & \multicolumn{4}{c}{ Confusion Matrix (\%) } \\
\cline { 2 - 5 } & Accuracy & Precision & Recall & F1-Score \\
\hline 0L & 83.89 & 78.24 & 83.89 & 80.97 \\
\hline 0R & 79.44 & 82.66 & 79.44 & 81.02 \\
\hline 1L & 74.44 & 70.16 & 74.44 & 72.24 \\
\hline 1R & 75 & 74.59 & 75 & 74.79 \\
\hline 2L & 73.33 & 58.93 & 73.33 & 65.35 \\
\hline 2R & 72.78 & 76.16 & 72.78 & 74.43 \\
\hline 3L & 57.22 & 72.54 & 57.22 & 63.98 \\
\hline 3R & 63.89 & 64.25 & 63.89 & 64.07 \\
\hline 4L & 93.33 & 93.85 & 93.33 & 93.59 \\
\hline 4R & 94.44 & 91.89 & 94.44 & 93.15 \\
\hline 5L & 92.22 & 98.22 & 92.22 & 95.13 \\
\hline 5R & 94.44 & 98.84 & 94.44 & 96.59 \\
\hline Overall & $\mathbf{7 9 . 5 4}$ & $\mathbf{8 0 . 0 3}$ & $\mathbf{7 9 . 5 4}$ & $\mathbf{7 9 . 6 1}$ \\
\hline \multicolumn{7}{c}{ Total Waktu Training } & $\mathbf{1 9 3 . 1 6}$ detik
\end{tabular}

H. Arsitektur LeNet menggunakan Average Pooling dengan Optimizer RMSprop

Hasil yang diperoleh pada skenario kedelapan dapat dlihat pada Tabel 15.

Tabel 15. Hasil Pengujian Skenario ke-8

\begin{tabular}{ccccc}
\hline \multirow{2}{*}{ Kelas } & \multicolumn{4}{c}{ Confusion Matrix $\mathbf{( \% )}$} \\
\cline { 2 - 5 } & Accuracy & Precision & Recall & F1-Score \\
\hline 0L & 100 & 100 & 100 & 100 \\
\hline 0R & 100 & 100 & 100 & 100 \\
\hline 1L & 99.44 & 97.81 & 99.44 & 98.62 \\
\hline 1R & 98.33 & 99.44 & 98.33 & 98.88 \\
\hline 2L & 98.89 & 98.34 & 98.89 & 98.61 \\
\hline 2R & 100 & 99.45 & 100 & 99.72 \\
\hline 3L & 98.33 & 99.44 & 98.33 & 98.88 \\
\hline 3R & 98.89 & 99.44 & 98.89 & 99.16 \\
\hline 4L & 100 & 100 & 100 & 100 \\
\hline
\end{tabular}




\begin{tabular}{|c|c|c|c|c|}
\hline $4 R$ & 100 & 100 & 100 & 100 \\
\hline $5 \mathrm{~L}$ & 100 & 100 & 100 & 100 \\
\hline $5 \mathbf{R}$ & 100 & 100 & 100 & 100 \\
\hline Overall & 99.49 & 99.49 & 99.49 & 99.49 \\
\hline \multicolumn{3}{|c|}{ Total Waktu Training } & \multicolumn{2}{|c|}{183.94 detik } \\
\hline
\end{tabular}

\section{Arsitektur LeNet menggunakan Average Pooling dengan Optimizer Adam}

Hasil yang diperoleh pada skenario kesembilan dapat dlihat pada Tabel 16.

Tabel 16. Hasil Pengujian Skenario ke-9

\begin{tabular}{ccccc}
\hline \multirow{2}{*}{ Kelas } & \multicolumn{4}{c}{ Confusion Matrix (\%) } \\
\cline { 2 - 5 } & Accuracy & Precision & Recall & F1-Score \\
\hline 0L & 99.44 & 98.35 & 99.44 & 98.9 \\
\hline 0R & 99.44 & 98.44 & 99.44 & 98.44 \\
\hline 1L & 95.56 & 92.97 & 95.56 & 94.25 \\
\hline 1R & 91.11 & 94.8 & 91.11 & 92.92 \\
\hline 2L & 95 & 90 & 95 & 92.43 \\
\hline 2R & 93.89 & 93.37 & 93.89 & 93.63 \\
\hline 3L & 90.56 & 94.77 & 90.56 & 92.61 \\
\hline 3R & 93.89 & 95.48 & 93.89 & 94.68 \\
\hline 4L & 98.89 & 97.8 & 98.89 & 98.34 \\
\hline 4R & 98.89 & 100 & 98.89 & 99.44 \\
\hline 5L & 100 & 100 & 100 & 100 \\
\hline 5R & 99.44 & 99.44 & 99.44 & 99.44 \\
\hline Overall & $\mathbf{9 6 . 3 4}$ & $\mathbf{9 6 . 3 7}$ & $\mathbf{9 6 . 3 4}$ & $\mathbf{9 6 . 3 4}$ \\
\hline Total Waktu Training & $\mathbf{3 2 3 . 7 3 3}$ detik \\
\hline \multicolumn{5}{c}{}
\end{tabular}

\section{J. Arsitektur LeNet menggunakan Max Pooling dengan Optimizer SGD}

Hasil yang diperoleh pada skenario kesepuluh dapat dlihat pada Tabel 17.

Tabel 17. Hasil Pengujian Skenario ke-10

\begin{tabular}{ccccc}
\hline \multirow{2}{*}{ Kelas } & \multicolumn{4}{c}{ Confusion Matrix (\%) } \\
\cline { 2 - 5 } 0L & Accuracy & Precision & Recall & F1-Score \\
\hline 0R & 82.22 & 90.24 & 82.22 & 86.05 \\
\hline 1L & 93.89 & 88.02 & 93.89 & 90.86 \\
\hline 1R & 83.33 & 83.33 & 83.33 & 83.33 \\
\hline 2L & 81.67 & 82.58 & 81.67 & 82.12 \\
\hline 2R & 72.78 & 74.43 & 72.78 & 73.6 \\
\hline 3L & 79.44 & 72.96 & 79.44 & 76.06 \\
\hline 3R & 76.67 & 78.86 & 76.67 & 77.75 \\
\hline 4L & 84.44 & 82.61 & 84.44 & 83.52 \\
\hline 4R & 93.89 & 82.86 & 93.89 & 93.37 \\
\hline 5L & 86.67 & 87.64 & 86.67 & 87.15 \\
\hline 5R & 97.22 & 96.69 & 97.22 & 96.95 \\
\hline Overall & $\mathbf{8 5}$ & 98.28 & 95 & 96.61 \\
Total Waktu Training & $\mathbf{8 5 . 7 1}$ & $\mathbf{8 5 . 6}$ & $\mathbf{8 5 . 6 1}$ \\
\hline
\end{tabular}

\section{K. Arsitektur LeNet menggunakan Max Pooling dengan Optimizer RMSprop}

Hasil yang diperoleh pada skenario kesebelas dapat dlihat pada Tabel 18.
Tabel 18. Hasil Pengujian Skenario ke-11

\begin{tabular}{ccccc}
\hline \multirow{2}{*}{ Kelas } & \multicolumn{4}{c}{ Confusion Matrix (\%) } \\
\cline { 2 - 5 } & Accuracy & Precision & Recall & F1-Score \\
\hline 0L & 98.89 & 93.34 & 98.89 & 98.61 \\
\hline 0R & 97.78 & 98.88 & 97.78 & 98.32 \\
\hline 1L & 96.67 & 92.06 & 96.67 & 94.31 \\
\hline 1R & 92.78 & 95.98 & 92.78 & 94.35 \\
\hline 2L & 96.11 & 96.11 & 96.11 & 96.11 \\
\hline 2R & 97.78 & 93.12 & 97.78 & 95.39 \\
\hline 3L & 95 & 95 & 95 & 95 \\
\hline 3R & 92.22 & 96.51 & 92.22 & 94.32 \\
\hline 4L & 98.33 & 98.33 & 98.33 & 98.33 \\
\hline 4R & 98.89 & 99.89 & 98.89 & 98.89 \\
\hline 5L & 99.44 & 100 & 99.44 & 99.72 \\
\hline 5R & 98.89 & 100 & 98.89 & 99.44 \\
\hline Overall & $\mathbf{9 6 . 9}$ & $\mathbf{9 6 . 9 4}$ & $\mathbf{9 6 . 9}$ & $\mathbf{9 6 . 9}$ \\
\hline Total Waktu Training & $\mathbf{1 8 3 . 9}$ detik
\end{tabular}

\section{Arsitektur LeNet menggunakan Max Pooling dengan Optimizer Adam}

Hasil yang diperoleh pada skenario keduabelas dapat dlihat pada Tabel 19.

Tabel 19. Hasil Pengujian Skenario ke-12

\begin{tabular}{ccccc}
\hline \multirow{2}{*}{ Kelas } & \multicolumn{4}{c}{ Confusion Matrix (\%) } \\
\cline { 2 - 5 } & Accuracy & Precision & Recall & F1-Score \\
\hline 0L & 96.67 & 96.67 & 96.67 & 96.67 \\
\hline 0R & 97.22 & 96.15 & 97.22 & 96.69 \\
\hline 1L & 86.67 & 88.14 & 86.67 & 87.39 \\
\hline 1R & 90.56 & 87.88 & 90.56 & 84.06 \\
\hline 2L & 87.78 & 80.61 & 87.78 & 84.04 \\
\hline 2R & 85.56 & 81.48 & 85.56 & 83.47 \\
\hline 3L & 81.67 & 84 & 81.67 & 82.82 \\
\hline 3R & 78.89 & 82.56 & 78.89 & 80.68 \\
\hline 4L & 94.44 & 85.51 & 94.44 & 94.97 \\
\hline 4R & 96.11 & 83.51 & 96.11 & 94.79 \\
\hline 5L & 97.78 & 97.74 & 97.78 & 97.51 \\
\hline 5R & 98.33 & 98.33 & 98.33 & 98.33 \\
\hline Overall & $\mathbf{9 0 . 1 4}$ & $\mathbf{9 0 . 1 7}$ & $\mathbf{9 0 . 1 4}$ & $\mathbf{9 0 . 1 2}$ \\
\hline \multicolumn{6}{c}{ Total Waktu Training } & $\mathbf{2 2 6 . 6 9}$ detik \\
\hline \multicolumn{5}{c}{}
\end{tabular}

\subsection{Analisis Hasil Pengujian}

Analisis yang akan dilakukan adalah dengan melakukan analisis perbandingan accuracy pada jenis pooling layer yang digunakan kemudian melakukan analisis perbandingan 12 skenario pengujian pada penelitian ini.

Gambar 6 menunjukkan hasil perbandingan akurasi dengan penggunaan Average Pooling masingmasing mendapatkan tingkat akurasi sebesar 99.45\% (AlexNet-RMSprop) serta 99.49\% (LeNet-RMSprop). 


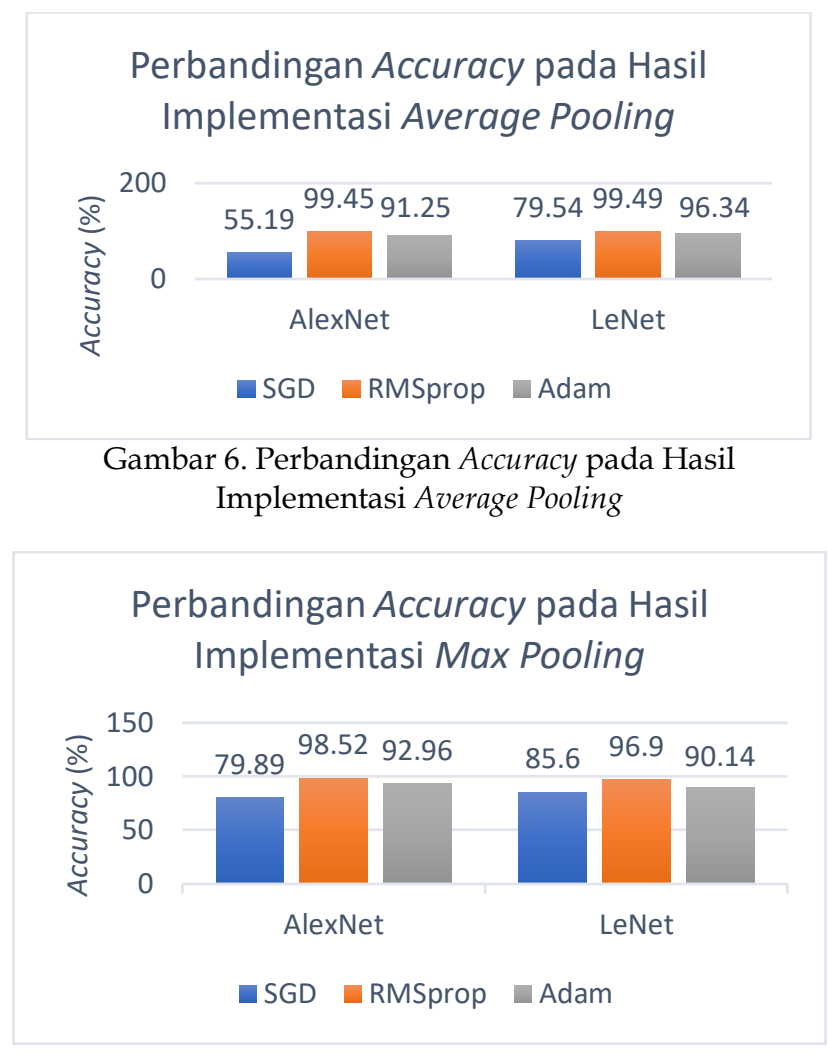

Gambar 7. Perbandingan Accuracy pada Hasil Implementasi Max Pooling

Gambar 7 menunjukkan Hasil perbandingan akurasi dengan penggunaan Max Pooling masingmasing mendapatkan tingkat akurasi sebesar $98.52 \%$ (AlexNet-RMSprop) kemudian pada arsitektur LeNet menghasilkan tingkat akurasi sebesar 96.9\% (LeNetRMSprop).

Kemudian perbandingan terhadap hasil skenario pengujian yang telah dilakukan secara keseluruhan yang dapat dilihat pada Gambar 8.

Hasil perbandingan klasifikasi pengujian terdapat 2 skenario pengujian terbaik dengan nilai keseluruhan accuracy, recall, precision, dan f1-score pada skenario AlexNet-AveragePooling-RMSprop sebesar 99,45\% dan LeNet-AveragePooling-RMSprop sebesar $99,49 \%$.

Jika dilihat dari jumlah parameter yang di-train AlexNet memiliki 98124 parameter sedangkan LeNet memiliki 62716 parameter. Namun hasil yang didapat dengan menggunakan LeNet memiliki selisih yang kecil yaitu $0,04 \%$. Jika berdasarkan jumlah parameter terlihat bahwa LeNet dengan parameter yang lebih sedikit dibandingkan AlexNet memberikan hasil yang lebih baik walaupun selisih hasil yang kecil. Jenis Pooling yang digunakan juga mempengaruhi hasil. Baik menggunakan AlexNet maupun LeNet, Average Pooling memberikan hasil paling baik dibandingkan dengan Max Pooling. Sama seperti pooling, optimizer baik pada AlexNet maupun LeNet, optimizer terbaik yaitu menggunakan RMSProp.

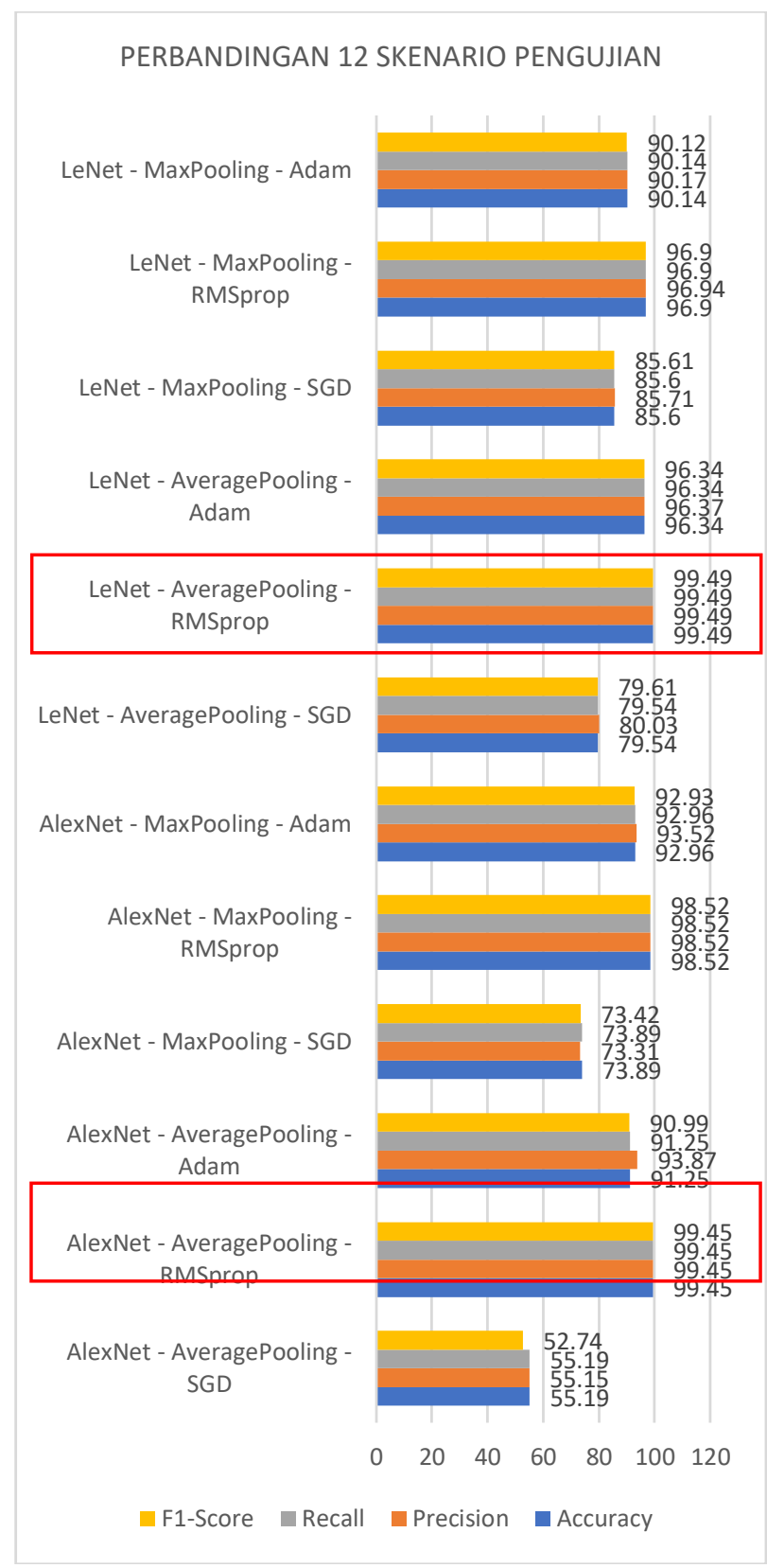

Gambar 8. Perbandingan 12 Skenario Pengujian

\section{KESIMPULAN}

Berdasarkan hasil penelitian yang telah dilakukan dapat ditarik beberapa kesimpulan. Penggunaan metode thresholding dapat membantu untuk mendeteksi objek gestur angka pada tangan dengan mendapatkan bentuk dari objek dan menghilangkan background objek. Penggunaan pooling layer dengan average pooling dan optimizer RMSprop pada arsitektur AlexNet maupun LeNet mendapatkan akurasi dan f1-score yang tertinggi dalam melakukan klasifikasi gestur angka pada tangan dengan nilai akurasi dan f1-score sebesar $99.45 \%$ (AlexNet) dan 99.49\% (LeNet). Untuk penelitian lebih lanjut pengenalan gestur angka bisa dengan menggunakan arsitektur yang lain. Selai itu dapat menggunakan pooling dan optimizer yang berbeda. 


\section{DAFTAR PUSTAKA}

[1] H. Purnama, Seni Bicara Bahasa Tubuh. Yogyakarta: Mantra Books, 2014.

[2] A. Sunyoto and A. Harjoko, "Review Teknik, Teknologi, Metodologi dan Implementasi Pengenalan Gestur Tangan Berbasis Visi," Semin. Nas. Apl. Teknol. Inf., p. H-7, 2014.

[3] J.-J. Park and C.-K. Kwon, "Korean Finger Number Gesture Recognition Based on CNN Using Surface Electromyography Signals," J. Electr. Eng. Technol., vol. 16, no. 1, pp. 591-598, Jan. 2021, doi: 10.1007/s42835-020-00587-3.

[4] M. Bagus, S. Bakti, and Y. M. Pranoto, "Pengenalan Angka Sistem Isyarat Bahasa Indonesia Dengan Menggunakan Metode Convolutional Neural Network," Semin. Nas. Inov. Teknol., pp. 11-16, 2019.

[5] M. E. Al Rivan, H. Irsyad, K. Kevin, and A. T. Narta, "Pengenalan Alfabet American Sign Language Menggunakan K-Nearest Neighbors Dengan Ekstraksi Fitur Histogram Of Oriented Gradients," J. Tek. Inform. dan Sist. Inf., vol. 5, no. 3, Jan. 2020, doi: 10.28932/jutisi.v5i3.1936.

[6] W. Kurniawan, "Program Aplikasi Komputer Pengenalan Angka Dengan Pose Jari Tangan Sebagai Media Pembelajaran Interaktif Anak Usia Dini," J. Sains dan Mat., pp. 68-73, 2012.

[7] H. Dafitri, M. S. Asih, and R. I. Astuti, "Media Interaktif Pengenalan Angka Dengan Jari Tangan Menggunakan Metode PCA ( Principal Component Analysis )," Query J. Sist. Inf., vol. 03, no. 02, pp. 57-65, 2019.

[8] R. M. Awangga, R. Andarsyah, and E. C. Putro, Tutorial Object Detection People With Faster regionBased Convolutional Neural Network(Faster RCNN). Jakarta: Kreatif, 2020.

[9] R. Rouhi, M. Jafari, S. Kasaei, and P. Keshavarzian, "Benign and malignant breast tumors classification based on region growing and CNN segmentation," Expert Syst. Appl., vol. 42, no. 3, pp. 990-1002, 2015, doi: 10.1016/j.eswa.2014.09.020.

[10] R. Rokhana, J. Priambodo, T. Karlita, I. M. G. Sunarya, E. M. Yuniarno, I. K. E. Purnama, M. H. Purnomo., "Convolutional Neural Network untuk Pendeteksian Patah Tulang Femur pada Citra Ultrasonik B-Mode," J. Nas. Tek. Elektro dan Teknol. Inf., vol. 8, no. 1, p. 59, 2019, doi: 10.22146/jnteti.v8i1.491.

[11] P. Koryakin, "Fingers," 2019. https://www.kaggle.com/koryakinp/fingers (accessed Jun. 13, 2021).

[12] M. E. Al Rivan and A. G. Riyadi, "Perbandingan Arsitektur LeNet dan AlexNet Pada Metode Convolutional Neural Network Untuk Pengenalan American Sign Language," J. Komput. Terap., vol. 7, no. 1, pp. 53-61, 2021, doi: https://doi.org/10.35143/jkt.v7i1.4489.

[13] I. W. S. E. Putra, A. Y. Wijaya, and R. Soelaiman, "Klasifikasi Citra Menggunakan Convolutional Neural Network (CNN) pada Caltech 101," J. Tek. ITS, vol. 5, no. 1, 2016, doi: 10.12962/j23373539.v5i1.15696.

[14] O. N. Putri, "Implementasi metode cnn dalam klasifikasi gambar jamur pada analisis image processing," Tugas Akhir. Universitas Islam Indonesia, 2020.

[15] W. Setiawan, "Perbandingan Arsitektur Convolutional Neural Network Untuk Klasifikasi Fundus," J. Simantec, vol. 7, no. 2, pp. 48-53, 2020, doi: 10.21107/simantec.v7i2.6551.

[16] S. Ilahiyah and A. Nilogiri, "Implementasi Deep Learning Pada Identifikasi Jenis Tumbuhan Berdasarkan Citra Daun Menggunakan Convolutional Neural Network," JUSTINDO (Jurnal Sist. dan Teknol. Inf. Indones., vol. 3, no. 2, pp. 49-56, 2018. 